\title{
Adaptação do teste de tetrazólio para avaliação da viabilidade e do vigor de sementes de girassol
}

\author{
Rosemeire Carvalho da Silva(1), Camila Ribeiro de Souza Grzybowski(1), José de Barros França-Neto(2) \\ e Maristela Panobianco ${ }^{(1)}$
}

\begin{abstract}
(1)Universidade Federal do Paraná, Departamento de Fitotecnia e Fitossanitarismo, Rua dos funcionários, № 1540, Juvevê, CEP 80035-050 Curitiba, PR. E-mail: rosemeirecarvalhosilva@gmail.com, camilaribeirodesouza@gmail.com, maristela@ufpr.br (2)Embrapa Soja, Caixa Postal 231, CEP 86001-970 Londrina, PR. E-mail: jbfranca@cnpso.embrapa.br
\end{abstract}

\begin{abstract}
Resumo - O objetivo deste trabalho foi avaliar metodologias para realização do teste de tetrazólio, na avaliação da viabilidade e do vigor de sementes de girassol, e estabelecer classes de qualidade para interpretação do teste. Foram avaliadas diferentes formas de extração do pericarpo e do tegumento das sementes, além do pré-condicionamento em água por 16 e 18 horas $\left(25^{\circ} \mathrm{C}\right)$ e da coloração em solução de tetrazólio $\left(30^{\circ} \mathrm{C}\right)$, nas concentrações de 0,1 e $0,5 \%$, por 2,3 e 4 horas; e de $1,0 \%$, por 1,2 e 3 horas. Após a definição da metodologia mais adequada para realização do teste, classes de vigor foram estabelecidas de acordo com a emergência das plântulas no campo. Foram identificadas cinco classes, as quais apresentaram correlação perfeita com a emergência. Para avaliar a viabilidade das sementes de girassol, o pericarpo e o tegumento devem ser retirados após corte longitudinal com até $1 / 3$ do comprimento da semente, o pré-condicionamento deve ser feito pela imersão em água por 16 horas, e a coloração deve ser realizada em solução de tetrazólio a $0,1 \%$, durante 3 horas.
\end{abstract}

Termos para indexação: Helianthus annuus, dormência, qualidade fisiológica.

\section{Adaptation of the tetrazolium test for assessment of sunflower seed viability and vigor}

\begin{abstract}
The objective of this work was to evaluate methodologies for performing the tetrazolium test in the evaluation of the viability and vigor of sunflower seeds, and to establish seed quality classes for test interpretation. Different methodologies were evaluated for extracting the pericarp and seed coat, besides water priming for 16 and 18 hours $\left(25^{\circ} \mathrm{C}\right)$, and staining with tetrazolium solution $\left(30^{\circ} \mathrm{C}\right)$ at the concentrations of 0.1 and $0.5 \%$, for 2,3 , and 4 hours; and of $1.0 \%$, for 1,2 , and 3 hours. After the definition of the most adequate methodology for performing the test, vigor classes were established according to seedling emergence on field. Five vigor classes were established, which had perfect correlation with seedling emergence. For the viability assessment of sunflower seeds, the pericarp and the seed coat should be removed after a lengthwise cut of up to $1 / 3$ seed length, water priming should be carried out for 16 hours, and staining should be done with tetrazolium solution at $0.1 \%$, during 3 hours.
\end{abstract}

Index terms: Helianthus annuиs, dormancy, physiological quality.

\section{Introdução}

A determinação rápida do potencial fisiológico das sementes é fundamental para que as empresas utilizem seus recursos de forma racional, e testes para avaliação do vigor das sementes têm grande importância na tomada de decisão quanto ao armazenamento e à comercialização do produto (TeKrony, 2003; Carvalho et al., 2009). Assim, diferentes procedimentos para a avaliação da qualidade das sementes têm sido empregados, principalmente os que permitem a identificação de lotes com alto ou baixo vigor (McDonald, 1998; Hampton, 2002; TeKrony, 2003).
A determinação da viabilidade de sementes de girassol pelo teste de germinação é relativamente demorada, especialmente se for necessário superar a dormência, o que estenderia o período de avaliação para, no mínimo, 17 dias (Regras para análise de sementes, 2009). Portanto, testes de avaliação do vigor de sementes baseados na avaliação do processo germinativo, tais como o de envelhecimento acelerado e os de avaliação do desempenho e da emergência de plântulas no campo, têm sua aplicação limitada a espécies que apresentam alto grau de dormência, como o girassol, em que a dormência é acentuada nos 40 dias 
após colheita (Bianco et al., 1994). O teste de tetrazólio é promissor nesses casos, uma vez que é um teste rápido (resultados fornecidos em menos de 24 horas), que não sofre influência da dormência das sementes, por se basear apenas no processo respiratório das células, e que permite a avaliação tanto da viabilidade quanto do vigor das sementes (Deswal \& Chand, 1997; Santos et al., 2007; Dias \& Alves, 2008; International Seed Testing Association, 2008).

Diversos autores têm abordado a adequação da metodologia do teste para várias espécies, como Oliveira et al. (2005), em sementes de canafístula; Chamma \& Novembre (2007), em milho; Kak et al. (2009) e Pinto et al. (2009), em pinhão-manso; Souza et al. (2010), em triticale; Costa \& Santos (2010), em leucena; e Clemente et al. (2011), em café. Para o girassol, entretanto, as recomendações para o teste de tetrazólio são feitas somente para a avaliação da viabilidade das sementes e variam de acordo com a International Seed Testing Association (2008) ou com as Regras para análise de sementes (2009), o que dificulta a uniformização das avaliações entre laboratórios. Quanto à avaliação do vigor, não há qualquer indicação para condução do teste.

O objetivo deste trabalho foi avaliar metodologias para realização do teste de tetrazólio, na avaliação da viabilidade e do vigor de sementes de girassol, e estabelecer classes de qualidade para interpretação do teste.

\section{Material e Métodos}

O trabalho foi realizado no Laboratório de Análise de Sementes do Departamento de Fitotecnia e Fitossanitarismo, da Universidade Federal do Paraná, em Curitiba, durante o período de setembro de 2010 a julho de 2011. Foram adquiridos 12 lotes de sementes da cultivar BRS 122 (safra 2010/2011). Entre esses, quatro lotes, com diferença significativa em sua qualidade fisiológica, foram selecionados para testar a sensibilidade das metodologias avaliadas as variações no vigor e na viabilidade das sementes. Os lotes foram homogeneizados em divisor centrífugo e divididos em quatro repetições. Durante o período experimental, as sementes foram armazenadas em ambiente controlado $\left(16 \pm 2^{\circ} \mathrm{C} ; 55 \%\right.$ UR).

O grau de umidade das sementes foi determinado pelo método de estufa a $105 \pm 3^{\circ} \mathrm{C}$ (Regras para análise de sementes, 2009). O teste de germinação foi conduzido após a completa superação da dormência das sementes (armazenamento por quatro meses, a $\left.16^{\circ} \mathrm{C} \pm 2 ; 55 \% \mathrm{UR}\right)$, tendo-se utilizado quatro repetições de 50 sementes (duas subamostras de 25 sementes por repetição) por lote. As sementes foram distribuídas em rolos de papel toalha umedecido com água, em quantidade equivalente a 2,5 vezes a massa do substrato seco, e colocadas para germinar a $25^{\circ} \mathrm{C}$. A avaliação foi realizada no sétimo dia após a semeadura, tendo-se registrado a percentagem de plântulas normais (Regras para análise de sementes, 2009).

Para determinar a maneira mais adequada de hidratação e de corte dos aquênios, com o intuito de facilitar a extração do pericarpo e do tegumento e de minimizar os danos aos cotilédones, as hidratações em papel (EP) e por imersão direta em água (IA) foram testadas por 16 horas, a $25^{\circ} \mathrm{C}$ (Concenço et al., 2007; Regras para análise de sementes, 2009), e foram feitos três diferentes tipos de corte. Tanto o corte longitudinal (entre os cotilédones) como o transversal foram realizados na porção superior das sementes, na região distal ao eixo embrionário, a 1/3 do comprimento total da semente. Avaliou-se, também, o corte lateral, realizado em toda a extensão do aquênio.

Para o teste de tetrazólio, utilizaram-se quatro repetições, de 50 sementes, para cada tratamento. As sementes foram hidratadas por imersão em água, durante 16 e 18 horas, a $25^{\circ} \mathrm{C}$ (Concenço et al., 2007; International Seed Testing Association, 2008). Após a hidratação, determinou-se o grau de umidade das sementes pelo método da estufa (Regras para análise de sementes, 2009).

Os embriões foram coloridos pela imersão em solução de 2, 3, 5 trifenil cloreto de tetrazólio, nas concentrações de 0,1 e $0,5 \%$, por 2,3 e 4 horas, e na concentração de 1,0\%, por 1, 2 e 3 horas, em ambiente escuro, a $30^{\circ} \mathrm{C}$ (International Seed Testing Association, 2008).

Após a definição da metodologia mais adequada para realização do teste de tetrazólio, foram realizadas avaliações para determinação de classes de qualidade das sementes, para interpretação do teste. Essas classes foram obtidas por meio da determinação da relação entre o valor do teste e a emergência das plântulas em campo. Antes, no entanto, a germinação foi novamente avaliada, conforme descrito anteriormente, mas com repetições de 100 sementes (quatro subamostras de 25 
sementes), ao invés de 50, para cada um dos quatro lotes de semente avaliado. A emergência das plântulas foi avaliada em canteiros, com quatro repetições de 100 sementes por lote, distribuídas em linhas equidistantes, com profundidade de semeadura de aproximadamente $4 \mathrm{~cm}$. A avaliação foi feita quando as plântulas atingiram a fase de emergência (VE), com o comprimento do primeiro par de folhas verdadeiras ainda menor que $4 \mathrm{~cm}$ (Castro \& Farias, 2005), e os resultados foram expressos em percentagem de plântulas emergidas.

Para determinação das classes de vigor das sementes, foram utilizadas 400 sementes por lote, submetidas à melhor combinação de pré-condicionamento e coloração obtida na etapa anterior do experimento, ou seja: pré-condicionamento por imersão direta em água durante 16 horas, a $25^{\circ} \mathrm{C}$, e coloração por imersão na solução de tetrazólio a $0,1 \%$, durante 3 horas, a $30^{\circ} \mathrm{C}$. Ao final do pré-condicionamento, determinou-se o grau de umidade das sementes pelo método da estufa (Regras para análise de sementes, 2009).

Após o término da coloração, as sementes foram lavadas em água corrente e mantidas submersas em água até o momento da avaliação, quando foram seccionadas longitudinalmente entre os cotilédones, com o auxílio de lâmina de aço inox, tendo-se obtido duas metades do embrião.

A avaliação dos tecidos externos e internos do embrião foi realizada com auxílio de microscópio estereoscópico, tendo-se observado, principalmente, as áreas vitais do embrião (cotilédones e eixo embrionário), e analisado a extensão e a intensidade da coloração. Os critérios de coloração basearam-se nas recomendações de Leist et al. (2003) e Regras para análises de sementes (2009).

O delineamento utilizado foi o inteiramente casualizado, com quatro repetições, e as médias foram comparadas pelo teste de Tukey, a 5\% de probabilidade. A viabilidade das sementes foi avaliada pela correlação de Spearman entre os valores do teste de tetrazólio e a germinação; e o vigor, pela correlação entre esses valores e a emergência de plântulas no campo. O teor de umidade das sementes não foi analisado estatisticamente.

\section{Resultados e Discussão}

A embebição dos aquênios diretamente em água proporcionou maior maciez ao pericarpo, em comparação à hidratação feita com papel, o que facilitou o corte e a completa extração do pericarpo e do tegumento aderidos ao embrião. Assim, a embebição em água, aliada ao corte longitudinal, realizado entre os cotilédones na porção de até $1 / 3$ do comprimento da semente, na região distal ao eixo embrionário, foi o procedimento mais adequado para o preparo das sementes.

Grzybowski et al. (2012), ao trabalharem com sementes de cevada, também obtiveram bons resultados com a hidratação por imersão direta em água, para a condução do teste de tetrazólio. Santos et al. (2012) utilizaram esse tipo de hidratação para realização do teste em amendoim.

O teor de umidade inicial das sementes variou, no máximo, 0,4 pontos percentuais entre os lotes (Tabela 1). Essa uniformidade é fundamental para a padronização das avaliações e a obtenção de resultados consistentes (Marcos Filho, 2005). Verificou-se, também, que o grau de umidade das sementes após o pré-condicionamento ficou entre 51 e $53,7 \%$ e entre 51 e 54,6\%, para 16 e 18 horas de hidratação, respectivamente. A diferença máxima na absorção de água pelas sementes, observada entre os períodos de 16 e 18 horas, foi de $1,6 \%$, o que indica que o pré-condicionamento pode ser realizado, sem prejuízos, por apenas 16 horas. Com esse período de hidratação, as sementes apresentaram grau de umidade superior a $45 \%$, comportamento similar ao comumente relatado na Fase I do modelo trifásico de hidratação (Bewley \& Black, 1983), para a maioria das sementes com reservas cotiledonares. Esse comportamento revela que a hidratação por este período é suficiente para reativar o metabolismo do embrião. Esses resultados estão de acordo com Concenço et al. (2007), que observaram

Tabela 1. Teor de umidade inicial e de umidade após o pré-condicionamento (PC) em água por 16 e 18 horas, e percentual de germinação dos quatro lotes de sementes de girassol utilizados ${ }^{(1)}$.

\begin{tabular}{|c|c|c|c|c|}
\hline \multirow[t]{2}{*}{ Lote } & \multirow{2}{*}{$\begin{array}{c}\text { Umidade } \\
\text { inicial }(\%)\end{array}$} & \multicolumn{2}{|c|}{ Umidade após o PC (\%) } & \multirow{2}{*}{$\begin{array}{c}\text { Germinação } \\
(\%)\end{array}$} \\
\hline & & 16 horas & 18 horas & \\
\hline 1 & 8,4 & 51,0 & 52,6 & $94 a$ \\
\hline 2 & 8,6 & 51,3 & 51,0 & $92 \mathrm{ab}$ \\
\hline 3 & 8,2 & 53,7 & 54,6 & $87 \mathrm{bc}$ \\
\hline 4 & 8,4 & 52,3 & 52,2 & $84 \mathrm{c}$ \\
\hline $\mathrm{CV}(\%)$ & - & - & - & 3,39 \\
\hline
\end{tabular}

${ }^{(1)}$ Médias seguidas de letras iguais não diferem pelo teste de Tukey, a $5 \%$ de probabilidade. 
estabilização na absorção de água pelas sementes de girassol após 16 horas de condicionamento.

Aavaliação inicial dos lotes de sementes (Tabela 1) foi importante para identificar aqueles com maior e menor potencial fisiológico, a fim de verificar a confiabilidade do teste de tetrazólio para essa finalidade (Deminicis et al., 2009). Pelo teste de germinação, os lotes 1 e 2 foram classificados como de maior qualidade, e o lote 4 apresentou o menor poder germinativo.

Foram identificadas três classes de viabilidade de sementes (Figura 1): classe 1, sementes viáveis, com tecidos firmes e coloração uniforme(vermelha carmim),

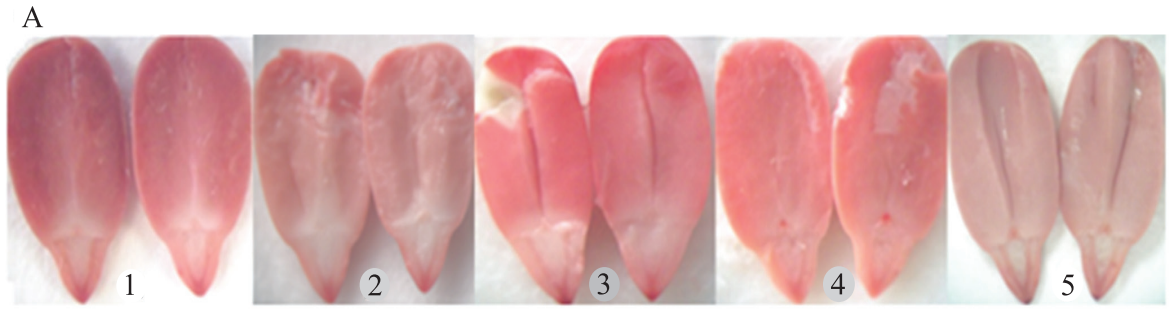

B

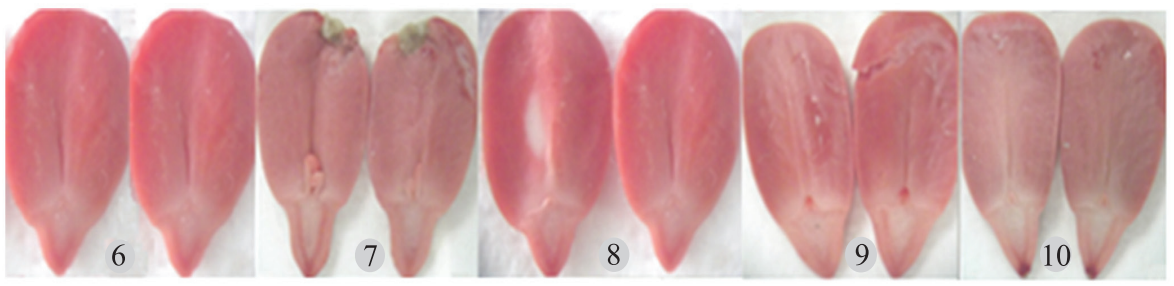

$\mathrm{C}$

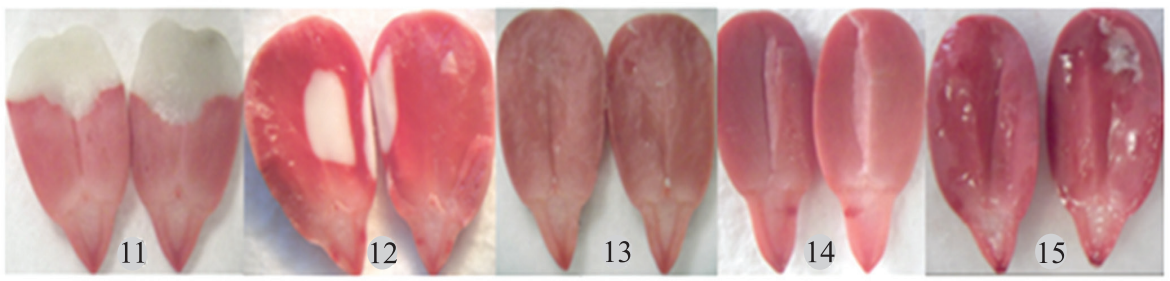

D

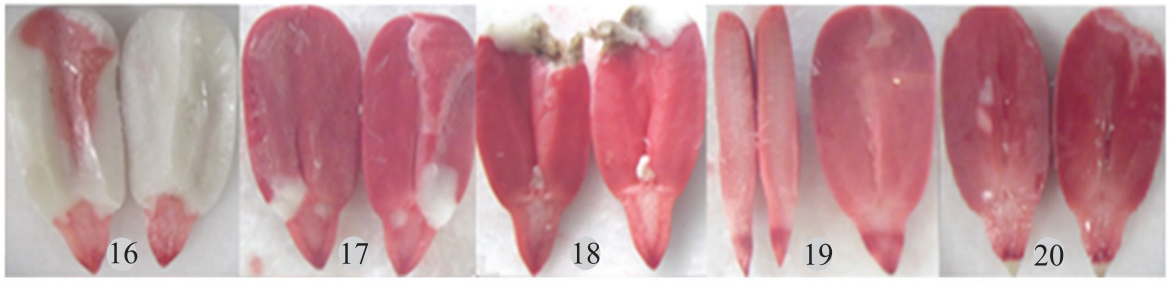

E

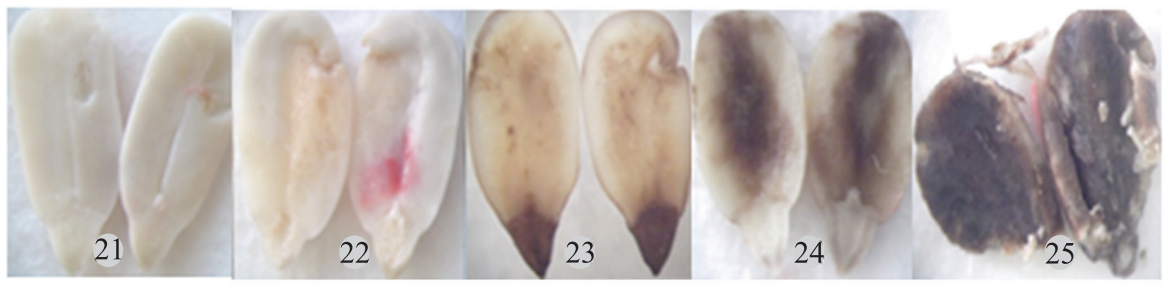

Figura 1. Classes de vigor obtidas pelo teste de tetrazólio, para sementes de girassol: A, classe 1 , sementes de alto vigor (fotos 1-5); B, classe 2, sementes de médio vigor (6-10); C, classe 3, sementes de baixo vigor (11-15); D, classe 4, sementes não viáveis (16-20); E, classe 5, sementes mortas (21-25). Aumento de 1,6 x no estereoscópio. 
em toda a extensão do embrião, sem que haja danos significativos para a germinação e o estabelecimento de plântulas normais; classe 2 , sementes não viáveis, com danos que comprometem o desenvolvimento normal da plântula; classe 3 , sementes mortas, sem respiração detectada em nenhum dos tecidos do embrião ou, ainda, com lesões escuras, em adiantado estágio de deterioração.

Quando o pré-condicionamento das sementes foi feito por 16 horas, o teste com os embriões expostos por 2 horas, à concentração de $0,1 \%$ da solução com tetrazólio, não possibilitou a separação dos lotes de acordo com a qualidade fisiológica das sementes (Tabela 2). A baixa concentração da solução, aliada ao curto período de exposição das sementes, pode ter causado essa menor precisão para distinguir a coloração dos tecidos, principalmente na região da plúmula, em que a coloração geralmente é menos intensa e dificulta a distinção entre tecidos vivos (colorido) e mortos (branco). Souza et al. (2010) relataram dificuldades na avaliação de estruturas essenciais das sementes de triticale, quando utilizaram solução na concentração de $0,1 \%$.

No entanto, no tratamento com exposição à solução de $0,1 \%$ por 3 horas (Tabela 2 ), observou-se que o teste foi sensível à qualidade fisiológica das sementes e possibilitou a separação dos lotes de forma semelhante à obtida no teste de germinação (Tabela 1), tendo-se identificado os lotes de menor potencial fisiológico (lotes 3 e 4). Porém, o período de 4 horas de coloração também não permitiu a separação dos lotes. Segundo Grzybowski et al. (2012), a coloração na concentração de $0,1 \%$ por 3 horas também se mostrou eficiente para avaliação do potencial fisiológico de sementes de cevada.

Com o pré-condicionamento por 18 horas, os resultados mais promissores também foram os obtidos com a coloração dos embriões por 3 horas, na solução de $0,1 \%$ (Tabela 2). Entretanto, essa combinação não permitiu identificar estatisticamente o lote 4 como o de menor viabilidade, de acordo com o teste de germinação (Tabela 1).

Metodologias eficientes, com utilização de solução de tetrazólio em baixas concentrações, são importantes para otimizar a aplicação dos recursos dentro dos laboratórios e possibilitar a análise de mais amostras com menor custo. Para grandes culturas, é comum que se recomende baixas concentrações de tetrazólio nas análises: 0,05\% para amendoim (Bittencourt \& Vieira, 1996); 0,075\% para soja (França Neto et al., 1999); e 0,1\% para algodão (Vieira \& Von Pinho, 1999). Pesquisas recentes, com várias espécies, têm confirmado a eficiência de baixas concentrações da solução de tetrazólio. É o caso, por exemplo, do uso recomendado de solução a $0,2 \%$ para Ricinus communis (Gaspar-Oliveira et al., 2009); a 0,15\% para Leucaena leucocephala $\mathrm{x}$ L. diversifolia (Costa \& Santos, 2010); a $0,01 \%$ para embriões de Olea europaea (Souza et al., 2011); e a 0,05\% para Arachis hypogaea (Santos et al., 2012).

Tabela 2. Viabilidade de sementes de girassol pelo teste de tetrazólio (\%), com pré-condicionamento por imersão em água, durante 16 e 18 horas, sob diferentes períodos de coloração, em solução de tetrazólio com três concentrações $(0,1,0,5$ e $1,0 \%)$ $\operatorname{distintas}^{(1)}$.

\begin{tabular}{|c|c|c|c|c|c|c|c|c|c|}
\hline \multirow[t]{2}{*}{ Lote } & \multicolumn{3}{|c|}{$0,1 \%$} & \multicolumn{3}{|c|}{$0,5 \%$} & \multicolumn{3}{|c|}{$1,0 \%$} \\
\hline & 2 horas & 3 horas & 4 horas & 2 horas & 3 horas & 4 horas & 1 hora & 2 horas & 3 horas \\
\hline & \multicolumn{9}{|c|}{ Pré-condicionamento por imersão em água por 16 horas } \\
\hline 1 & $90 \mathrm{a}$ & $88 \mathrm{ab}$ & $94 \mathrm{a}$ & $91 \mathrm{a}$ & $85 \mathrm{a}$ & $85 \mathrm{a}$ & $81 \mathrm{a}$ & $86 \mathrm{ab}$ & $77 \mathrm{a}$ \\
\hline 2 & $94 \mathrm{a}$ & $92 \mathrm{a}$ & $90 \mathrm{a}$ & $85 \mathrm{a}$ & $87 \mathrm{a}$ & $90 \mathrm{a}$ & $85 \mathrm{a}$ & $93 a$ & $80 a$ \\
\hline 3 & $89 a$ & $84 b$ & $87 a$ & $86 a$ & $85 a$ & $82 \mathrm{a}$ & $76 a$ & $78 \mathrm{~b}$ & $73 a$ \\
\hline 4 & $89 a$ & $86 b$ & $89 a$ & $82 \mathrm{a}$ & $87 \mathrm{a}$ & $86 a$ & $79 a$ & $86 b$ & $74 a$ \\
\hline \multirow[t]{2}{*}{ CV (\%) } & 3,6 & 3,4 & 5,4 & 6,6 & 4,2 & 6,8 & 6,5 & 5,6 & 7,0 \\
\hline & \multicolumn{9}{|c|}{ Pré-condicionamento por imersão em água por 16 horas } \\
\hline 1 & $92 \mathrm{a}$ & $90 \mathrm{ab}$ & $90 \mathrm{a}$ & $79 b$ & $87 \mathrm{a}$ & $92 \mathrm{a}$ & $90 \mathrm{a}$ & $88 \mathrm{a}$ & $87 \mathrm{a}$ \\
\hline 2 & $94 \mathrm{a}$ & $93 a$ & $93 \mathrm{a}$ & $86 \mathrm{a}$ & $88 \mathrm{a}$ & $87 \mathrm{ab}$ & $91 \mathrm{a}$ & $90 \mathrm{a}$ & $83 \mathrm{ab}$ \\
\hline 3 & $88 \mathrm{a}$ & $83 b$ & $88 \mathrm{a}$ & $81 \mathrm{ab}$ & $84 \mathrm{a}$ & $82 b$ & $88 \mathrm{a}$ & $83 \mathrm{a}$ & $78 b$ \\
\hline 4 & $89 a$ & $88 \mathrm{ab}$ & $88 \mathrm{a}$ & $78 b$ & $83 a$ & $86 a b$ & $87 a$ & $82 \mathrm{a}$ & $87 a$ \\
\hline CV (\%) & 3,3 & 4,1 & 5,6 & 3,7 & 6,0 & 3,3 & 5,5 & 5,3 & 4,2 \\
\hline
\end{tabular}

${ }^{(1)}$ Médias seguidas de letras iguais não diferem pelo teste de Tukey, a 5\% de probabilidade. 
A utilização da solução de $0,5 \%$, no pré-condicionamento por 16 horas (Tabela 2), também não permitiu detectar diferenças na viabilidade dos lotes, de acordo com a germinação (Tabela 1), independentemente do período de coloração testado. A concentração de $0,5 \%$ proporcionou coloração um pouco mais intensa dos tecidos, quando comparada à concentração de $0,1 \%$, o que, na prática, pode influenciar a interpretação da viabilidade dos tecidos, especialmente nas áreas mais críticas, como na região do hipocótilo-radícula.

O sucesso da interpretação do teste de tetrazólio é dependente da experiência prática do analista, principalmente para identificar nuances das colorações mais escuras e mais fracas, em relação às observadas na coloração normal dos tecidos viáveis (Marcos Filho, 2005). Neste sentido, com a experiência adquirida durante o período de realização do trabalho, pode-se dizer que o uso da concentração mais baixa permitiu identificar detalhes sutis que influenciaram a interpretação dos resultados.

$\mathrm{O}$ uso de 18 horas para pré-condicionamento (Tabela 2) não aumentou a relação dos resultados do teste de tetrazólio a $0,5 \%$ com a germinação das sementes (Tabela 1), visto que, neste caso, os lotes $1 \mathrm{e}$ 4 apresentaram-se estatisticamente iguais.

$\mathrm{O}$ uso da concentração de 1,0\%, com pré-condicionamento por 16 horas e coloração por 1 hora ou 3 horas, não permitiu diferenciar os lotes (Tabela 2). No entanto, quando a coloração foi realizada por 2 horas, foi possível a separação dos lotes de menor potencial fisiológico, de forma semelhante à obtida na avaliação da germinação (Tabela 1).

$\mathrm{O}$ tratamento com pré-condicionamento das sementes por 18 horas (Tabela 2) e coloração a 1,0\% por 3 horas está entre as metodologias indicadas para sementes de girassol (International Seed Testing Association, 2008; Regras para análise de sementes, 2009). Contudo, a classificação da viabilidade por este método não foi coerente com a obtida com o teste de germinação, uma vez que o lote de maior qualidade (lote 1) não diferiu do lote de menor qualidade (lote 4).

Além disso, a avaliação das sementes imersas na concentração de $1,0 \%$ exige maior cuidado, já que, independentemente do período de exposição, a coloração foi intensa, o que dificulta a distinção dos tecidos viáveis daqueles em deterioração. No caso do girassol, a região mais crítica para ser avaliada foi a do eixo embrionário, especialmente na extremidade da radícula, em razão da forte coloração, provavelmente influenciada pela maior atividade respiratória no local. Assim, diversos cortes foram necessários para identificar a extensão e a profundidade da coloração nos tecidos, o que tornou a avaliação mais demorada e exaustiva.

De acordo com os resultados obtidos, considerouse, portanto, que o uso da solução de tetrazólio a $0,1 \%$, com 16 horas de pré-condicionamento, é o mais adequado para determinação das classes de viabilidade das sementes de girassol. Antes da definição dessas classes, no entanto, constatou-se que os lotes estavam uniformes quanto à umidade inicial (Tabela 3), característica importante para obtenção de resultados consistentes. A homogeneidade inicial contribuiu para que a absorção de água pelas sementes, após 16 horas de hidratação, tenha sido uniforme, com pequena diferença no teor de umidade final entre os lotes (máxima de 2,7\%).

No teste de germinação, realizado para determinação das classes de viabilidade (Tabela 3 ), verificou-se que os lotes 1 e 2 eram de melhor qualidade, em comparação ao lote 3. Os resultados obtidos, na avaliação da

Tabela 3. Teor de umidade inicial e de umidade após o pré-condicionamento em água por 16 horas, percentual de germinação e de emergência no campo, e resultados do teste de tetrazólio (TZ) para viabilidade e vigor das sementes dos quatro lotes utilizados $^{(1)}$.

\begin{tabular}{|c|c|c|c|c|c|c|}
\hline Lotes & Umidade inicial & Umidade 16 horas & Germinação & Emergência & $\mathrm{TZ}$ viabilidade & $\mathrm{TZ}$ vigor \\
\hline 1 & 8,4 & 51,0 & $85 \mathrm{a}$ & $94 \mathrm{ab}$ & $91 \mathrm{a}$ & $77 b$ \\
\hline 2 & 8,6 & 51,3 & $86 \mathrm{a}$ & $95 \mathrm{a}$ & $92 \mathrm{a}$ & $82 \mathrm{a}$ \\
\hline 3 & 8,2 & 53,7 & $76 b$ & $87 \mathrm{c}$ & $82 b$ & $68 \mathrm{c}$ \\
\hline 4 & 8,4 & 52,3 & $81 \mathrm{ab}$ & $92 b$ & $86 b$ & $74 b$ \\
\hline $\mathrm{CV}(\%)$ & - & - & 4,9 & 1,29 & 1,94 & 2,08 \\
\hline
\end{tabular}

${ }^{(1)}$ Médias seguidas de letras iguais não diferem pelo teste de Tukey, a 5\% de probabilidade.

Pesq. agropec. bras., Brasília, v.48, n.1, p.105-113, jan. 2013

DOI: 10.1590/S0100-204X2013000100014 
emergência de plântulas no campo, ressaltaram a superioridade do lote 2 e o menor desempenho do lote 3 , com desempenho intermediário dos lotes 1 e 4.

$\mathrm{Na}$ análise da viabilidade das sementes pelo teste de tetrazólio (Tabela 3), foi possível a separação dos lotes de forma semelhante à obtida com o teste de germinação, com a classificação dos lotes 3 e 4 como de qualidade inferior aos lotes 1 e 2 .

Na realização do teste de tetrazólio para avaliação do vigor das sementes, também adotou-se a metodologia mais adequada, determinada na primeira etapa. Foram identificadas cinco classes de vigor das sementes.

A classe 1 apresentou sementes de alto vigor (Figura 1), com tecidos firmes e coloração uniforme (vermelha carmim) em toda a extensão do embrião (fotos 1 e 2), não tendo apresentado danos significativos para o estabelecimento de plântulas normais (3 a 5). Assim, para que as sementes fossem classificadas nesta classe, os danos tolerados abrangiam área de até $1 / 3$ sem coloração, na extremidade superior de apenas um dos cotilédones (3), ou área inferior a 1/3 com coloração vermelha carmim mais intensa, na extremidade das plúmulas (4). Além disso, a presença de pequenos sinais (pontos) com coloração mais intensa na região do eixo hipocótilo-radícula (5), sem que estes tenham atingido a região do cilindro central, também não inviabilizou o enquadramento das sementes nesta classe.

A classe 2 apresentou sementes de médio vigor: cotilédones com coloração vermelha carmim mais intensa, superficialmente (foto 6); danos com área de até $1 / 3$ da extremidade de ambos os cotilédones (7); dano na região vascular central em um dos cotilédones (8), desde que este não tenha atingido a região de união entre o cotilédone e o eixo embrionário; e cotilédones com plúmulas com coloração mais intensa em até $50 \%$ de sua extremidade (9), ou, ainda, com coloração mais intensa em área de até $1 / 3$ da extremidade da radícula (10), sem que o cilindro central tenha sido comprometido.

A classe 3 apresentou sementes de baixo vigor: danos que abrangiam até $50 \%$ dos cotilédones (região sem coloração, foto 11); danos presentes na região vascular em ambos os cotilédones (12), desde que não tenham atingido a região de união entre os cotilédones e o eixo embrionário; região sem coloração até $50 \%$ da extremidade das plúmulas (13); e danos na região do hipocótilo-radícula (14), desde que estes tenham atingido extensão inferior a
$50 \%$ do cilindro central, ou, ainda, quando o tecido sem coloração tenha área de até $1 / 3$ da extremidade da radícula (15), sem que o cilindro central tenha sido comprometido.

A classe 4 apresentou sementes não viáveis: danos superiores a $50 \%$ da área total dos cotilédones (foto 16) ou quando estes atingiram a região de união dos cotilédones ao eixo embrionário (17); dano superior a $50 \%$ da área das plúmulas (18); bem como danos na região do cilindro central (19); e danos com mais de $1 / 3$ de área na extremidade da radícula, com comprometimento do cilindro central (20).

A classe 5 apresentou sementes mortas, que não apresentaram coloração em toda a extensão do embrião (foto 21), e tecidos moles (22) ou com regiões escuras, em adiantado estágio de deterioração (23-25).

$\mathrm{O}$ vigor das sementes foi representado pelo total de sementes classificadas nas duas primeiras classes, enquanto a viabilidade foi composta pela soma das três primeiras classes. As classes 4 e 5 somaram o total de sementes não viáveis.

Tanto na avaliação do vigor pelo teste de tetrazólio, como na avaliação da emergência de plântulas no campo, foi possível separar o lote 2 como o de maior vigor, em comparação ao lote 3; enquanto os lotes 1 e 4 foram considerados de médio vigor (Tabela 3). Para que se tenha segurança na separação entre sementes de alto ou baixo vigor, o teste deve apresentar resultados condizentes aos da emergência em campo. Neste sentido, a avaliação das sementes de girassol pelo teste de tetrazólio foi eficiente, visto que os resultados foram relacionados tanto à análise da viabilidade quanto à do vigor.

As correlações de Spearman entre os testes de germinação e de tetrazólio (tendo-se somado as três primeiras classes para totalizar as sementes viáveis), bem como entre os testes de emergência e de tetrazólio (tendo-se somado as duas primeiras classes para totalizar a percentagem de sementes vigorosas) obtiveram o índice de $\rho=1,0$, ou seja, correlação perfeita entre os testes com probabilidade de 0,041 .

Portanto, o teste de tetrazólio pode ser utilizado na avaliação do vigor das sementes de girassol, uma vez que a sua elevada correlação com a emergência de plântulas em campo confere confiabilidade para a classificação de lotes. 


\section{Conclusão}

A avaliação da qualidade fisiológica (viabilidade e vigor) das sementes de girassol por meio do teste de tetrazólio é eficiente com o emprego do condicionamento direto em água por 16 horas e da imersão em solução de tetrazólio na concentração de $0,1 \%$, por 3 horas.

\section{Referências}

BEWLEY, J.D.; BLACK, M. Physiology and biochemistry of seeds in relation to germination: development, germination, and growth. New York: Springer, 1983. v.1., 306p.

BIANCO, J.; GARELLO, G.; LE PAGE-DEGIVRY, M.T. Release of dormancy in sunflower embryos by dry storage: involvement of gibberellins and abscisic acid. Seed Science Research, v.4, p.57-62, 1994. DOI: 10.1017/S0960258500002026.

BITTENCOURT, S.R.M.; VIEIRA, R.D. Use of reduced concentrations of tetrazolium solutions for the evaluation of the viability of peanut seed lots. Seed Science and Technology, v.2, p.75-82, 1996.

CARVALHO, L.F. de; SEDIYAMA, C.S.; REIS, M.S.; DIAS, D.C.F.S.; MOREIRA, M.A. Influência da temperatura de embebição da semente de soja no teste de condutividade elétrica para avaliação da qualidade fisiológica. Revista Brasileira de Sementes, v.31, p.9-17, 2009. DOI: 10.1590/S0101-31222009000100001.

CASTRO, C. de; FARIAS, J.R.B. Ecofisiologia do girassol. In: LEITE, R.M.V.B. de C.; BRIGHENTI, A.M.; CASTRO, C. de (Ed.). Girassol no Brasil. Londrina: Embrapa Soja, 2005. p.163-218.

CHAMMA, H.M.C.P.; NOVEMBRE, A.D. da L.C. Teste de tetrazólio para as sementes de milho: períodos de hidratação e de coloração das sementes. Revista Brasileira de Sementes, v.29, p.125-129, 2007. DOI: 10.1590/S0101-31222007000200017.

CLEMENTE, A. da C.S.; CARVALHO, M.L.M. de; GUIMARÃES, R.M.; ZEVIANI, W.M. Preparo das sementes de café para avaliação da viabilidade pelo teste de tetrazólio. Revista Brasileira de Sementes, v.33, p.38-44, 2011. DOI: 10.1590/ S0101-31222011000100004.

CONCENÇO, G.; COMIOTTO, A.; MORAIS, D.M. de; LOPES, N.F.; FERREIRA, L.B.O. Sulfentrazone e a qualidade fisiológica das sementes de girassol. Revista Brasileira de Agrociência, v.13, p.109-113, 2007.

COSTA, C.J.; SANTOS, C.P. dos. Teste de tetrazólio em sementes de leucena. Revista Brasileira de Sementes, v.32, p.66-72, 2010. DOI: $10.1590 /$ S0101-31222010000200008.

DEMINICIS, B.B.; VIEIRA, H.D.; SILVA, R.F. da. Teste de tetrazólio para avaliação da qualidade de sementes de Clitorea ternatea L. Revista Brasileira de Sementes, v.31, p.54-62, 2009. DOI: $10.1590 / \mathrm{S} 0101-31222009000200006$.

DESWAL, D.P.; CHAND, U. Standardization of the tetrazolium test for viability estimation in ricebean (Vigna umbellata (Thunb.)
Ohwi \& ohashi) seeds. Seed Science and Technology, v.25, p.409-417, 1997.

DIAS, M.C.L. de L.; ALVES, S.J. Avaliação da viabilidade de sementes de Panicum maximum Jacq pelo teste de tetrazólio. Revista Brasileira de Sementes, v.30, p.152-158, 2008. DOI: 10.1590/S0101-31222008000300020.

FRANÇA NETO, J.B.; KRZYZANOWSKI, F.C.; COSTA, N.P. Metodologia do teste de tetrazólio em sementes de soja. In. KRZYZANOWSKI, F.C.; VIEIRA, R.D.; FRANÇA NETO, J. de B. (Ed.). Vigor de sementes: conceitos e testes. Londrina: ABRATES, 1999. p.1-28.

GASPAR-OLIVEIRA, C.M.; MARTINS, C.C.; NAKAGAWA, J. Concentração da solução de tetrazólio e período de coloração do teste para sementes de mamoneira. Revista Brasileira de Sementes, v.31, p.38-47, 2009. DOI: 10.1590/S0101-31222009000300004.

GRZYBOWSKI, C.R. de S.; OHLSON, O. de C.; SILVA, R.C. da; PANOBIANCO, M. Viability of barley seeds by the tetrazolium test. Revista Brasileira de Sementes, v.34, p.47-54, 2012. DOI: 10.1590/S0101-31222012000100006.

HAMPTON, J.G. What is seed quality? Seed Science and Technology, v.30, p.1-10, 2002.

INTERNATIONAL SEED TESTING ASSOCIATION. Biochemical test for viability: topographical tetrazolium test. In: INTERNATIONAL rules for seed testing. Bassersdorf: ISTA, 2008. Chap.6, p.1-30.

KAK, A.; PANDEY, C.; GUPTA, V. Assessment of viability of Jatropha curcas L. seeds using the tetrazolium test. Seed Science and Technology, v.37, p.512-515, 2009.

LEIST, N.; KRÄMER, S.; JONITZ, A. (Ed.). Working sheets on tetrazolium testing. Bassersdorf: International Seed Testing Association, 2003. v.1, 171p.

MARCOS FILHO, J. Fisiologia de sementes de plantas cultivadas. Piracicaba: Fealq, 2005. 495p.

MCDONALD, M.B. Seed quality assessment. Seed Science Research, v.8, p.265-276, 1998. DOI:10.1017/ S0960258500004165.

OLIVEIRA, L.M. de; CARVALHO, M.L.M. de; DAVIDE, A.C. Teste de tetrazólio para avaliação das sementes de Peltophorum dubium (Sprengel) Taubert - Leguminosae Caesalpinioideae. Cerne, v.11, p.159-166, 2005.

PINTO, T.L.F.; MARCOS FILHO, J.; FORTI, V.A.; CARVALHO, C. de; GOMES JUNIOR, F.G.J. Avaliação da viabilidade das sementes de pinhão manso pelos testes de tetrazólio e de raios X. Revista Brasileira de Sementes, v.31, p.195-201, 2009. DOI: 10.1590/S0101-31222009000200023.

REGRAS para análise de sementes. Brasília: Ministério da Agricultura, Pecuária e Abastecimento, 2009. 395p.

SANTOS, J.F.; SANCHES, M.F.G.; BARBOSA, R.M.; LEÃO, E.F.; VIEIRA, R.D. Optimising tetrazolium test procedures to evaluate the physiological potential of peanut seeds Seed Science and Technology, v.40, p.215-228, 2012. 
SANTOS, M.A.O; NOVEMBRE, A.D.L.C.; MARCOS FILHO, J. Tetrazolium test to assess viability and vigour of tomato seeds. Seed Science and Technology, v.35, p.213-223, 2007.

SOUZA, C.R. de; OHLSON, O. de C.; GAVAZZA, M.I.A.; PANOBIANCO, M. Tetrazolium test for evaluating triticale seed viability. Revista Brasileira de Sementes, v.32, p.163-169, 2010. DOI: $10.1590 / \mathrm{S} 0101-31222010000300018$.

SOUZA, R.A.V. de; BRAGA, F.T.; VIEIRA NETO, J.; MENDONÇA, E.A.F. de; AZEVEDO, P.H. de; CANÇADO, G.M. de A. Viabilidade e germinação de embriões de oliveira submetidos a diferentes condições de armazenamento de frutos. Pesquisa Agropecuária Brasileira, v.46, p.309-314, 2011. DOI: 10.1590/ S0100-204X2011000300012.

TEKRONY, D.M. Precision is an essential component in seed vigour testing. Seed Science and Technology, v.31, p.435-447, 2003.

VIEIRA, M.G.G.C.; VON PINHO, E.V.R. Metodologia do teste de tetrazólio em sementes de algodão. In. KRZYZANOWSKI, F.C.; VIEIRA, R.D.; FRANÇA NETO, J. de B. (Ed.). Vigor de sementes: conceitos e testes. Londrina: Abrates, 1999. p.1-13.

Recebido em 23 de abril de 2012 e aprovado em 7 de janeiro de 2013 